\title{
The Poor and the Pandemic- COVID 19
}

\author{
Sanjeev Thakur \\ Medical Intern, Department Of Community Medicine, Jawaharlal Nehru Medical College, Datta Meghe Institute \\ Of Medical Sciences, Wardha. \\ Email ID- sanjeevthakur58293@gmail.com
}

Review Article

Conflict of Interest: None

\begin{abstract}
The pandemic of coronavirus disease commonly known as covid 19 is known to be caused by severe acute respiratory syndrome coronavirus 2 (SARS-CoV-2) has led to public health concern. The infection is known to be transmitted via respiratory droplets during close face to face contact with an infected individual or may be transmitted by asymptomatic individual. The time from exposure to symptom onset is estimated to be around 14 days. The most common symptoms are fever, dry cough and shortness of breath. In fight against the infection, the Government of India imposed nationwide lockdown from 24 March ,2020 onwards to prevent the spread of infection. The Government of India claims to have won battle against the pandemic by stating that the number of cases would have been higher if nationwide lockdown had not been imposed. However this claimed is being questioned as the number of cases is on the rise each day we see. In this brief review, we aim to discuss the impact of pandemic covid 19 on poor people of India.
\end{abstract}

Keywords- Pandemic, Covid 19, SARS-CoV-2, Lockdown,Asymptomatic

\section{INTRODUCTION}

What is coronavirus disease? Why it has created so much imbalance in the society? Why it is so important to be aware particularly about this disease? In brief, "coronavirus is nothing but large,enveloped,single-stranded RNA viruses found in humans and other mammals". The mode of transmission of severe acute respiratory syndrome coronavirus 2 occcurs through respiratory droplets from face to face contact with an infected individual who may be symptomatic or asymptomatic at the moment and to a lesser extent from the contaminated surfaces.[1].When an infected individual who is symptomatic or asymptomatic coughs, sneeze or talk, the virus particle is released in air; when an healthy individual breathes this air, the virus gets trapped into the nasal mucosa and enters the body. Common symptoms observed in infected individual are fever, dry cough, shortness of breath,fatigue,diarrhoea,nausea, vomiting, loss of taste and smell sensation, headache.[2]. The person might present

with any one or two or three symptom or may be asymptomatic. Commonly observed laboratory findings in hospitalized patients were reduced lymphocytes level, increased in the levels of inflammatory markers such as tumor necrosis factor-alpha, erythrocyte sedimentation rate (ESR), C-reactive protein, interleukin-1, interleukin-6, ferritin levels. Other abnormal coagulation parameters include low platelet count, increased d-dimer levels, increased prothrombin time, low fibrinogen levels. Commonly observed radiological findings include lower lobe both lung involvement showing ground glass opacities and infiltrates on chest x-rays. CT scan of chest (computed tomographic) shows consolidation in lung parenchyma. The disease is said to show complications in some individual. Commonly observed complications are pneumonia, acute respiratory distress syndrome, liver injury causing rise in liver enzymes like alanine 
transaminase, aspartate transaminase, bilirubinlevels. Some individuals have also shown cardiac injury including elevated troponin levels, heart failure, arrythmias, myocarditis, prothrombotic coagulopathy. Some have also presented with acute kidney injury, neurological manifestations, cerebrovascular disease and shock.[3-8]Severely ill patients have experienced "cytokine storm" and "macrophage activation syndrome" which is "secondary hemophagocytic lymphohistiocytosis".

The infection can be detected by doing a test called "reverse transcription polymerase chain reaction" or by rapid antigen testing. The former test requires a swab collected from nasopharynx of the patient. The sensitivity and accuracy of "reverse transcription polymerase chain reaction" is far more than that of rapid antigen testing. The latter is believed to give false negative which makes it less reliable test. The virus is also found in faeces but not detected in urine.[9]. Saliva of the person can be collected besides other sample and is quite non-invasive. Serological testing may also help in the diagnosis of infection. It is found that immunoglobulin $M$ antibodies can be detected within 5 to 6 days of exposure while immunoglobulin $\mathrm{G}$ can be detected 14 days after symptom onset.[10,11]

The infection can be prevented by wearing a mask, social distance of approximately 6 feet from one another, hand hygiene. Mask available in market which significantly prevents transmission of infection are surgical mask,N-95 mask. Cloth mask are not that much recommended. Maintaining a distance of 6 feet from each other along with wearing a mask in public significantly reduced the chance of infection. Frequent washing of hand with a soap or handwasher or sanitizing with an alcohol based sanitizer reduced the spread of infection. As a prophylaxis vitamin supplements especially vitamin $\mathrm{C}$ and zinc are recommended. Foods and fruits rich in vitamin $\mathrm{c}$ are recommended. Steam inhalation and gargle with betadine or salt in hot water is being recommended. Isolation of confirmed and suspected cases[12].

There is no specific treatment as such. But the drugs recommended are antibiotics like doxycycline,azithromycin;antiparasitic drug ivermectin, vitamin $\mathrm{C}$, zinc supplements,antiviral drugs like remdesivir,

flavipiravir;dexamethasone,tocilizumab, statins,paracetamol,cough syrup. Oxygenation through High flow nasal cannula or non-invasive ventilation is recommended in hypoxic patients, Lastly convalescent plasma therapy.

\section{IMPACT OF PANDEMIC ON SOCIETY AND POOR}

The measures taken to contain COVID-19 has influence family units from various perspectives, including position trouble, loss of house, greater costs, imbalance in food and other essential products, and interruptions to medical care administrations and instruction. While the effects felt by most families were very quick, they will probably be more profound and longer-enduring among poor people, who are more defenceless for a few reasons:

The poor live basically in provincial zones. This would in turn increase the risk of catching infection, it likewise implies they have restricted admittance to wellbeing administrations. In addition, since provincial family units will in general rely more upon homegrown settlements from metropolitan travellers, financial closures in metropolitan territories will hurt them as well. The poor in metropolitan territories, then again, live in blocked settlements with bad quality administrations, which would fundamentally expand their danger of being contaminated by the virus. 
Interruptions in food markets could be more extreme in metropolitan regions.

The helpless work generally in the agribusiness and administration areas and are normally independently employed or casually utilized, mostly in miniature and family endeavours. The workers who are being used to do simpler work in metropolitan regions are more vulnerable to faced the serious side effects. Furthermore, a considerable lot of the weak non-poor, who are progressively utilized in the gig economy, especially in center pay nations, will likewise be in danger of slipping into neediness. Those who are involved in farming activities might have the option to adapt, in any event at first, with expected hindrance to food supplies or rise in the price, but have a fair chance to be influenced by a decrease sought after in metropolitan territories after some time $[13,14]$.

High reliance on open administrations, especially wellbeing and instruction. In the prompt term, restricted admittance to high-calibre and reasonable wellbeing administrations can have destroying impacts in case of a disease in the family, while school terminations can result in decrease in food intake by children of poor families who depend on school taking care of their child through various services. The long term impact of closure may result in youth intercessions, wellbeing registration, and nourishment which can be very well observed in kids of poor families, thereby influencing their human resources improvement and acquiring potential. Restricted reserve funds and absence of admittance to protection. This, without sufficient wellbeing nets, can compel the poor to depend on adapting methodologies to possible enduring negative impacts, for example, the offer of beneficial resources or lessened interests in human resources $[15,16]$.
The experience of influenced nations proposes that the rate and effects of COVID-19 can shift altogether across space and over the long haul, with metropolitan territories being the hardest hit at first. Rigid wellbeing control measures have brought an enormous portion of monetary movement to a stop, leaving numerous metropolitan poor and powerless without an approach to earn enough to pay the bills. The danger of interruptions to the food supply and markets could likewise be higher in metropolitan territories, while and the capacity of families to manage expected deficiencies or costs climbs for food and other need things could be lower.

Simultaneously, governments' ability to rapidly turn out revenue backing to influenced family units in these regions is restricted. Existing wellbeing net projects generally target provincial regions, and backing for organizations most likely will just profit those in the proper area. Accordingly, a large number of the new helpless will probably be found in urban communities, while country regions, which will in general be less fortunate to begin with, will encounter a decay in everyday environments and an extending of destitution.To the unaided eye, the infection has been aimless. It has influenced the youthful and old. Affluent and ruined. Metropolitan and rustic. It is even affected the world's most extravagant nations first. Furthermore, hit them hard. For each person, it has carried life to a stop. A more obscure reality, in any case, has all the while arisen. It is one that has consistently prowled out of sight: it is the least fortunate residents of India, the ones who as of now face the brunt of India's gigantic disparities, that will experience the ill effects of this present pandemic's enduring impacts.

Those residents are in reality the transient specialists whose predicament 
has brought us nerve racking stories. However, they are likewise the every day breadwinners, retailers, cabbies, servers, cooks, woodworkers, and that's just the beginning. These families contribute more than $80 \%$ of India's economy. Large numbers of them are bankrupt or have lost their positions; and they have no social security net $[17,18]$.

"The COVID-19 pandemic has led to unimaginable loss of human life in the country and across the world and has brought human life to standstill. The economic and social imbalance caused by the pandemic is upsetting as millions of people have lost their jobs and are at the risk of falling below poverty. Due to this, there has been an increase in the number of undernourished people in the country. With no means to earn an income during lockdown, people are unable to feed themselves and their families".

The pandemic has badly affected the food system of the country and across the world. Boundary closure, trade restrictions and other restrictions led by the government have been keeping buyers and sellers from getting to business sectors, also looking for the information sources and selling their goods, and horticultural laborers from reaping crops, ultimately leading to collapse of food system of the country and diminishing admittance to solid, protected and assorted weight control plans. The pandemic has affected various sector and services which have resulted in loss of jobs and created an imbalance in society. As people are unable to trade properly they give up, the food security and the people wellbeing are in danger, with those in underdeveloped countries where people are paid less, especially the most underrated groups, which involves limited buyers and sellers group and people of local community, get badly affected.

A huge number of farming experts who are working on their own face significant levels of working destitution, unhealthiness and long term frailty, and experience the side effects of an absence of wellbeing and work insurance just as different sorts of misuse. Low pay and an absence of social help, forces a great number of lower income groups to work in unfavourable environment, putting them and their families in danger. Due to financial problem, it may force them to adapt wrong techniques, for example, trouble offer of resources, ruthless advances or child labour. Focusing on the wellbeing and strength of the people involved in food system -from farmers to those engaged with food handling, transport and retail, including vendors on road -giving them better earnings and insurance, will be sufficient in saving lives and securing general wellbeing, individuals' occupations and food security. In such emergency cases food safety, general wellbeing, business and work related problems, specifically workers' wellbeing and safety merge. Ensuring safe working environment, decentpay, jobsecurity, will help in restoring the workers wellbeing and their safety. As pandemic has already caused a huge loss, with cooperation with the government; this could be achieved. Thus securing the low paid workers and their families. Special care has to be taken for females who are working in this scenario. Help in the form of money, families food security, securing child's future may prove to be useful. In planning and achieving such goals it is basic that the government work intimately with the owners and workers.

The horticultural yields, animals and fisheries are not exempted from the effect of COVID-19. Being a rural nation, the movement limitation and lockdown have influenced each phase of the food store network, including food creation and appropriation in India. Ranchers are constrained to dump milk and vegetables after a critical decline in inventory and 
conclusion of handling organizations and appropriate business sectors. This has prompted unexpected value climb, dark advertising and lack of items in the markets. While the public authority is asking individuals to follow isolating and restricting get-together of individuals, a huge number of ranchers need to assemble to plant food and money crops in India with the appearance of the storm. The current lockdown measures may assist the public authority with crushing this infection, yet in the event that the examples of limited scope planting, reaping and appropriation keep on being upset, many thousands will lose their vocations, and the entire country could slip into profound food frailty. Accordingly, the public authority ought to authorize measures to control the pandemic without upsetting the food inventory network and considering the food security of their residents.

Lockdown imposement caused people to stay in their home. Service class people who rely on their monthly wage, started using their savings for their daily needs. As lockdown extended, savings of the people were nearly over and they felt the need to step out of their house and start doing any job that would help them to survive during this pandemic. People started risking their life and went out of their house and started doing the work which even paid them less. Less payment and working in unsafe environment affected the psychology of the person. Anxiety and Fear of getting infected while working and infecting our loved ones while coming back to home started taking place in our mind. This resulted in mental breakdown of the person. Due to lockdown; many people lost their jobs. People who were living on rent in cities were compelled to leave the house as they were unable to pay the rents and went back to their villages. This resulted in migration of people in large numbers from urban cities to rural villages. These migrants also faced the problem of social indiscrimination as the cases in cities were more. They were not allowed to enter the village[19-22].

Due to high demand of sanitizers and mask; their price went so high that poor people could not afford to buy the basic safety things that would keep them safe. If at all any poor people got infected; they could not get bed in hospitals for the treatment as beds in hospitals were already occupied or reserved for rich people or special people. Medicines price also went high due to their increase demand. Sometimes medicines were not available in medical shops. Due to such circumstances the death rate among the poor people were more.

The poor people of India mainly lives in slums. Social distancing which is practically impossible in such scenario makes them most vulnerable to catch infection. Poor hygiene and lack of safety equipment makes them more vulnerable to catch infection.

The pandemic also affected the educational system of the country. Closure of schools caused digitalization in education. The concept of Virtual learning came into existence. So the need of internet connectivity and smart phones became basic requirement of todays education. Poor people who could not afford smart phones or access to internet were devoid of their education. This somehow contributed to child labour as the child were sent out of the home by their parent to earn for their families.

\section{CONCLUSION}

The pandemic has affected all section of the society whether rich or poor, young or old. But the most affected ones are the poor people of the society. The pandemic resulted in loss of job which eventually caused financial problem and one of the reason of migration of people from urban cities to rural areas. No income means no food for the poor people which resulted in undernourishment. No job, no 
money in the home forced people to step out of their house in this pandemic and earn for their living. People were ready to work even at low wages. Unsafe environment and low wages led to mental breakdown. Anxiety and fear of getting infected affected the psychology of the person. Increased demand of mask, sanitizer resulted in rise in their price which became difficult for poor people to afford the basic safety things. Expensive hospital treatment, unavailability of beds in hospitals resulted in death of poor people. Social indiscrimination became one of the problem in society. Farmers were unable to sell their growing and were forced to dump their product. Digitalization in education contributed to child labour as poor people could not have access to virtual learning. Migrant labourers walked miles bare-footed from urban cities to their village as there were no mode of transport available during the time of pandemic. There was increase in the suicidal rate and incidence of depression among poor people. Our Prime Minister of India launched "Garib Kalyan Rojgar" scheme for migrant workers with a view to increase rural employment, especially among migrant workers who have returned home during the COVID-19 19 lockdown. Many rich people of the society have also try to help the weaker section of the society with the help of the government and local administration.

\section{REFERENCES}

[1] Ganyani T, Kremer C, Chen D, et al. Estimating the generation interval for coronavirus disease (COVID-19) based on symptom onset data, March 2020. Euro Surveill. 2020;25(17). doi:10.2807/1560-7917.ES.2020.25. 17.2000257

[2] Mao R, Qiu Y, He JS, et al. Manifestations and prognosis of gastrointestinal and liver involvement in patients with
COVID-19: a systematic review and meta-analysis. Lancet

Gastroenterol $\quad$ Hepatol.
2020;5(7):667-678.
doi:10.1016/S2468-1253(20)30126-6

[3] Levi M, Thachil J, Iba $T$, Levy JH. Coagulation abnormalities and thrombosis in patients with COVID-19. Lancet Haematol. 2020;7(6):e438-e440. doi:10.1016/S2352-3026(20)30145-9

[4] Long B, Brady WJ, Koyfman A, Gottlieb M. Cardiovascular complications in COVID-19. Am $J$ Emerg Med. Published online April 18, 2020. doi:10.1016/j.ajem.2020.04.048

[5] Mao L, Jin H, Wang $M$, et al. Neurologic manifestations of hospitalized patients with coronavirus disease 2019 in Wuhan, China. JAMA Neurol. 2020;77(6):1-9. doi:10.1001/jamaneurol.2020.1127

[6] Middeldorp S, Coppens M, van Haaps TF, et al. Incidence of venous thromboembolism in hospitalized patients with COVID-19. J Thromb Haemost. Published online May 5, 2020. doi:10.1111/jth.14888

[7] Chen YT, Shao SC, Hsu CK, $\mathrm{Wu} \quad \mathrm{IW}$, Hung $\mathrm{MJ}$, Chen YC. Incidence of acute kidney injury in COVID-19 infection: a systematic review and meta-analysis. Crit Care. 2020;24(1):346. doi:10.1186/s13054-020-03009-y

[8] Rodriguez-Morales AJ, Cardona-Ospina JA, Gutiérrez-Ocampo E, et al; Latin American Network of Coronavirus Disease 2019-COVID-19 Research (LANCOVID-19). Clinical, laboratory and imaging features of COVID-19: a systematic review and meta-analysis. Travel Med Infect 
Dis.

2020;34:101623. doi:10.1016/j.tmaid.2020.101623

[9] Wang W, Xu Y, Gao R, et al. Detection of SARS-CoV-2 in different types of clinical specimens. JAMA.

2020;323(18):1843-1844. doi:10.1001/jama.2020.3786

[10] Sethuraman N, Jeremiah SS, Ryo A. Interpreting diagnostic tests for SARS-CoV-2. JAMA. Published online May 6, 2020. doi:10.1001/jama.2020.8259

[11]Guo L, Ren L, Yang S, et al. Profiling early humoral response to diagnose novel coronavirus disease (COVID-19). Clin Infect Dis. Published online March 21, 2020. doi:10.1093/cid/ciaa310.

[12] Milan, S. and Treré, E., 2020. <? covid19?> The Rise of the Data Poor: The COVID-19 Pandemic Seen From the Margins. Social Media+ Society, 6(3), p.2056305120948233.

[13] Ingale, A.K., and P. Shrivastav. "Role of Ayurveda for Poor and Pandemics (Covid19) - a Review Article." International Journal of Research in Pharmaceutical Sciences 11, no. Special Issue 1 (2020): 923-27. https://doi.org/10.26452/ijrps.v11iSP L1.3163.

[14] Padole, V.S., R.P. Kalsait, R. Ambad, and P. Kute. "Effect of COVID 19 Affecting Geriatric Patients." International Journal of Current Research and Review 12, no. 17 (2020): 182-87. https://doi.org/10.31782/IJCRR.2020 .121729.

[15] Waghmare, A., S. Shrivastava, and S. Date. "Effect of Covid-19 Lockdown in Trauma Cases of Rural India." International Journal of Research in Pharmaceutical Sciences 11, no. Special Issue 1 (2020): 365-68. https://doi.org/10.26452/ijrps.v11iSP L1.2727.
[16] Agrawal, D., N. Khara, B. Mundada, N. Bhola, and R. Borle. "COVID-19 and Its Financial Effects on the Dental Fraternity and Health-Care Workers: A Literature Review." International Journal of Research in Pharmaceutical Sciences 11, no. Special Issue 1 (2020): 628-31. https://doi.org/10.26452/ijrps.v11iSP L1.2883.

[17]Bakshi, S., V. Toshniwal, A. Agrawal, S. Acharya, and S. Shukla. "Awareness and Psychosocial Effects of Covid-19 Pandemic on Health Care Professionals and Medical Students across the State of Maharashtra." International Journal of Current Research and Review 12, no. 22 Special Issue (2020): S-122-S-125.

https://doi.org/10.31782/IJCRR.2020 .SP74.

[18]Gaidhane, S., N. Khatib, Q.S. Zahiruddin, A. Gaidhane, S. Telrandhe, and P. Godhiwal. "Depression, Anxiety and Stress among the General Population in the Time of COVID-19 Lockdown: A Cross-Sectional Study Protocol." International Journal of Research in Pharmaceutical Sciences 11, no. Special Issue 1 (2020): 360-64. https://doi.org/10.26452/ijrps.v11iSP L1.2726.

[19]Regmi, P.R., E. van Teijlingen, P. Mahato, N. Aryal, N. Jadhav, P. Simkhada, Q.S. Zahiruddin, and A. Gaidhane. "The Health of Nepali Migrants in India: A Qualitative Study of Lifestyles and Risks." International Journal of Environmental Research and Public Health 16, no. 19 (2019). https://doi.org/10.3390/ijerph161936 55.

[20]Adhikary, P., N. Aryal, R.R. Dhungana, R.K. Kc, P.R. Regmi, K.P. Wickramage, P. Duigan, et al. "Accessing Health Services in India: 
Experiences of Seasonal Migrants Returning to Nepal." BMC Health Services Research 20, no. 1 (2020). https://doi.org/10.1186/s12913-020-0 5846-7.

[21] Aryal, N., P.R. Regmi, E. van Teijlingen, P. Simkhada, and P. Mahat. "Adolescents Left behind by Migrant Workers: A Call for Community-Based Mental Health Interventions in Nepal." WHO South-East Asia Journal of Public Health 8, no. 1 (2019): 38-41. https://doi.org/10.4103/2224-3151.25 5348.

[22] Aryal, N., P.R. Regmi, E. van Teijlingen, S. Trenoweth, $P$. Adhikary, and P. Simkhada. "The Impact of Spousal Migration on the Mental Health of Nepali Women: A Cross-Sectional Study.” International Journal of Environmental Research and Public Health 17, no. 4 (2020). https://doi.org/10.3390/ijerph170412 92. 